Narratives, connections and social change

Narratives, connections and social change 
Narratives, connections and social change 
Narratives, connections and social change

In this article, I suggest that narratives' importance for social change may be understood by examining specific elements of narrative syntax - key rhetorical tropes within stories, and story genres. I argue that these stylistic elements generate social connections that themselves support and stimulate social change. I use Young's (2006) theorisation of responsibility and global justice in terms of connection, to suggest how narratives may support or generate progressive social change. I then examine narrative tropes and genres of similarisation and familiarisation at work in narratives produced around the HIV pandemic, and the limits of those tropes and genres for supporting and catalysing social change. 
Narratives, connections and social change

\section{Narratives, connections and social change}

\section{To appear in Narrative Inquiry, 2012. Please quote published version.}

\section{Narratives and social research}

You have shared your stories of struggle, you have spoken of your dreams, along the way, talking with all of you (sic) about your own lives.

Barack Obama's election eve speech, November 8, 2008 (Obamaspeeches.com 2008 )

In President Obama's election campaign speeches, as the opening quotation from one of them shows, stories had an important place. Stories bridged national differences, they addressed difficult issues such as 'race' and they linked the present to the past and to possible futures. The speeches explicitly foregrounded stories, suggesting they promoted understanding because they showed socio-historical context and contest in ways that generated dialogue and commonality. Stories were presented as grounding the 'hope' and 'change' rhetoric of the campaign, and enabling progressive action. They operated as explanation, but also morally. They recorded the macrosocial past of racialised discrimination, as well as the microsocial past of families; they gave children "a sense of obligation and debts to be paid to earlier generations." Stories were the means of imagining the future, transmitting "struggles...hopes and dreams" (Obamaspeeches.com 2008). In addition, stories gave Obama's speeches a strong transnational currency; the "struggles...hopes and dreams" he narrated seemed to speak to many outside as well as within the US. Sometimes straightforward, sometimes complex and multilayered, the stories generated lines of connection within the campaign. 
Narratives, connections and social change

Former New York governor Mario Cuomo famously associated campaign with poetry, government with prose. Certainly, campaign and office demand different forms of speech. In office, personal stories ceded to history in many of Obama's important early speeches - the inaugural speech, the Nobel Prize acceptance speech. Stories retained a stronger role in addresses that did not have immediate policy implications. The first Fathers' Day, NAACP, and Memorial Day speeches, the speech after the Tucson shootings, and the 2011 State of the Union address are examples (Klein 2011). Yet some commentators, criticising Obama for lack of political focus, decried his lack of a unifying 'narrative' (Stevenson 2010). Others lamented a lack of expressed emotion, especially in his apparently cool response to crises (Linkins 2010). Personal narratives, complex and connecting, were perhaps part of what was missing from early presidential speeches that seemed dispersed or formalistic.

How does the Obama example of a commitment to narrative, alongside a curtailment of it, relate to social research's concern with narratives and social change? Social researchers are similarly ambiguous about narrative. Charles Tilly, for instance, a proponent of narratives' social usefulness, nevertheless emphasised the "trouble with stories” (2002: 25-44). For him, stories have many positive social functions. They are good at "patching social life together....cementing people's commitment to common projects, helping people make sense of what is going on, channelling collective decisions and judgements, spurring people to action they would otherwise be reluctant to pursue." They help people recognise difficulties in their own understandings and actions (2002: 26-7). They convey meaning in vivid ways and help us understand the links between individuals, social change, and politics (1985; 2002; Stanley 2009). Nevertheless, for 
Narratives, connections and social change

social researchers, Tilly argued, stories have explanatory constraints. They deal in small numbers of characters, limited timespans, and a sequentiality that simplifies causality.

Tilly's qualified endorsement of narratives' significance for social research helpfully exemplifies the important but ambivalent place of narrative within contemporary sociology. In the wake of his work, and Obama's storytelling retrenchment, I aim to analyse some aspects of the strong but limited significance of stories for social change. I will do this not by describing the overall functions of narratives, as Tilly and indeed Obama have done, but by investigating particular aspects of narrative that seem to contribute importantly to narratives' ability to catalyse social change. The aspects of narrative considered in this article belong to the categories of genres, that is, patterns of plot, character and theme (Todorov 1990), and tropes such as similes and metaphors - forms of rhetoric that play a key role in narratives' progressions. I examine how these elements of narrative may generate social change by sustaining and enabling social connections. First, though, I consider how links between narratives and change are conceptualised within narrative research.

\section{Narrative and social change}

Empirical research on personal narratives indicates their importance not just for psychological change, but also for broader transformations to which I will here give the general name of 'social change.' Social change does not, of course, always move in progressive directions. Nonetheless its primary meaning within social and political theory and philosophy is of a move towards improvement, emancipation, equality and justice, and it is in this sense that I 
Narratives, connections and social change

shall use the term here. Keeping this meaning in mind, personal narratives are argued to be important for understandings of, for instance, historical shifts (Bertaux 1981; Portelli 1990; 2007); social formations and social movements (Polletta 2006; Tilly and Tarrow 2006; White 2008), political resistance (Andrews 2007; Gready 2008; Selbin 2010), changing patterns of youth culture and education (Georgakopoulou 2007; Xu and Connelly 2010) and social and cultural moves in discourses and practices around illnesses and abuse (M. Hydén 2008; Radley 2009). Narratives are also viewed as socially significant beyond the academic realm. Human rights, for example, are often claimed and expressed through first-person narratives (Shaffer and Smith 2004). Medical addresses to illness increasingly include patient or survivor narratives (DIPEx 2010; Hearing Voices Network 2010). Personal stories are seen as crucial to understanding patterns of migration and memory (Azarian-Ceccato 2010; Eastmond 2007) that are shaping the transnational world.

Social researchers often relate narrative's centrality in such work to its binding of the personal to the social realm. Personal narratives, appearing in social interactions or in popular media, emblematise a western 'autobiographical age’ dominated by first-person stories (Plummer 2001; Stanley 1996). Within this age, ethico-political argument is founded on individual subjects (MacIntyre 1984), and self-narratives are socio-moral necessities (Butler 2005). Personal narratives thus work to constitute effective, moral subjects and citizens. Such arguments appear within many key works on narrative within social and psychological research (Bruner 2002, Sarbin 1986, Freeman 2009, Riessman 2008). Moreover, the strong contemporary currency of 'personal narrative' does not rest only on first-person stories told spontaneously about things that happened to the narrator (Labov 1997). Powerful personal stories can be told about other people and distant events; in the first person plural, as stories about 'us'; in testimonio form, with the 7 
Narratives, connections and social change

narrator speaking for a collective (Beverley 2004); as imaginings of the future (Patterson, 2008); in interested and intertextual accounts that resonate with other such narratives rather than aiming to provide faithful accounts of events $\left(^{*}\right)$ - and through writing, visual and object 'narratives' as well as speech.

Social researchers also argue that narrative is central to social change because of its intrinsic relationship with personal and social progress. Considerable debate attends this assertion. This debate derives partly from theoretical accounts of narratives as inevitably fragmented, nonlinear, and socially and politically variable or non-aligned ${ }^{\mathrm{i}}$ (Barthes 1977; Butler 2005; Culler 2006). These accounts also emphasise that narratives' power can function, like other kinds of power, in different directions, 'for' as well as 'against' conservatism and inequality (Foucault 1980). Such characterisations come into conflict with more traditional concepts of narratives as coherent, closed, hegemonic and oriented towards equality and progress. Relatedly, it is clear that narratives do not fully determine the material world. Frequently, indeed, they operate outside social functionality; it may not be possible to say what they 'mean', let alone whether they produce progressive or other kinds of change. Functionalist approaches to what narratives ‘do’ tend to underestimate narratives’ relatively autonomous operations as forms of language that in themselves generate pleasure, pain, contradictions, uncertainties and irrelevancies. Such difficulties appear empirically in the often incoherent, incomplete and ineffectual character of narratives studied by social researchers (Hydén and Brockmeier 2008; Hyvärinen et al. 2010; Riessman 2008). However, complexities in narratives' relationship to social change do not obviate the possibility that the relationship is important and sometimes progressive. 
Narratives, connections and social change

From varied assumptions about the change-oriented nature of narratives, stem varied conceptualisations of their links with social change. Social researchers argue diversely that personal narratives can mirror changing social conditions (Bertaux 1981); elucidate processes of social change and the place of individuals within them (Andrews 2007); contribute to the interplay between cultural and political change (Polletta 2006) and catalyse social change (Plummer 1995; Polletta and Lee 2006; *). Francesca Polletta describes a metonymical connection, in Student Non-violent Coordinating Committee (SNCC) stories told within the organisation in the mid-1960s, between decentralised, participatory structures, and lack of political direction and white domination. The connection the stories articulated seems to have stimulated, even generated a shift towards centralisation. More broadly, Kenneth Plummer (1995) describes a set of mid-twentieth century potentiations by intimate disclosure narratives about personal suffering, of social and legal change around male violence, sexual abuse and harrassment, and gay and lesbian sexualities.

For some, stories constitute a form of change in themselves. Spivak (1996) argues that a variety of different kinds of materials can work as theory - activist texts, empirical materials, personal stories - with political effects. This suggests that everyday stories may not always be preliminary or 'lay’ explanations subordinate to social science theory (Labov 1997; Ricoeur 1991; Tilly 2006). Instead, they can operate as effective accounts of phenomena, particularly those not already theorised, that enable change. In my early-2000s research with people living with HIV in South Africa, for instance, in a context where silence or pathologising stories about HIV were widely said to contribute to difficulties in living with the condition, HIV positive interviewees' stories of 'speaking out' about HIV seemed to help them theorise themselves as moral and political subjects, and in the process accept their illness, disclose, seek treatment, 9 
Narratives, connections and social change

educate others and campaign for services (*).

This article adopts a formulation of narrative as theory, because that formulation allows us to take into account narratives' specific yet tangential relationship to change. Narrative is not a direct change agent like economic redistribution, legal reform, political activism or neighborhood reconstruction. It works in a material but mediating manner, consolidating, resisting and shifting representational realities. Through these processes, it operates as a potentiating theorisation of social change. In cases where representation is a foregrounded aspect of the political field, it may itself be an important element of social change.

What is the evidence for narratives’ social effects? As described by Plummer, Polletta, Tilly and others, stories impact and are affected by multiple, overlapping social processes; specific narratives’ effects are hard to isolate. A contextualised, rich description can in many circumstances provide a better understanding of narratives' social efficacy than can a unidirectional causal explanation of a particular narrative’s effects (Mishler 1986). Some researchers are pursuing this kind of work within practice-based or ethnographic narrative inquiry, an approach that often comes close to a narrative version of participatory action research, studying the changes effected by sets of stories in circulation within a particular 'life world'(Gubrium and Holstein 2009; Xu and Connelly 2010). The findings from such work are illuminating, though hard to generalise. As an alternative, I want to look at how specific narrative strategies operating within a particular field, but to describe them in generalisable ways.

What are the appropriate objects of study when researching narratives’ social 
Narratives, connections and social change

effectiveness? Any breakdown of narrative into component parts will over-formalise stories’ complexities. However, Mishler's (1986) categorisation of narrative content, context and syntax is a fruitful heuristic. Within this framework, content is the usual object chosen for study; but content is not the only basis for stories' effects. If it were, the specifically narrative character of stories would not matter; they could equally well be treated as for instance discourses, conversations or themes $(*)$. Narrative context - its interpersonal, institutional and sociocultural situating - is a growing focus of research, and includes narrative positioning, practice and performance (Bamberg 2006; Riessman 2008; Xu and Connelly 2010). Content itself may be parsed as an artefact of context, or as inextricable from it. Again, though, analyses of context may subordinate narratives’ specific characteristics to narratives’ conditions of existence and effectiveness.

A third possible focus for research on narratives’ social effects is narrative syntax, which includes stories' clause structure, cognitive units, genres, and tropes or 'figures of speech.' Once more, this field can be understood as an aspect of 'context', that is, as determined by the possibilities offered by and understood within a particular historico-cultural field. Content is also relevant to it. Cognitive units or clauses contain specific content; genres are defined by patterns of plot, theme and character; the content of key narrative similes and metaphors shapes their effectiveness (Lakoff and Johnson 2003; Todorov 1990). However, the autonomy of the field is again important. Narrative syntax has effects, as language, that are relatively independent from the effects of its meanings and practice.

Narrative syntax is often viewed as the most low-level field to analyse, the least political and least related to social change. However, studying the syntax of texts means paying attention 
Narratives, connections and social change

to persistent and powerful but often neglected elements of language. In the case of narratives, this research focus also addresses their most characteristic elements. For almost every definition of narrative specifies some kind of movement - temporal, spatial, causal, relational, moral or aesthetic - that is, a syntactic structure within stories, which operates at differing levels, from overarching genre progressions, through clause and idea structures, down to the rhetorical effects of single words. Two of these syntactic elements - genres, and smaller but narratively key elements of rhetoric - are the objects of my consideration here.

Some narrative research points to particular syntactic elements that relate to change - for instance, the intimate disclosure genre that builds identificatory communities of listeners (Plummer 1995); metonymical linkages and the trope of 'spontaneity’ within social change stories (Polletta 2006); cultural genres at work within shifting personal stories (Edley 2002; *); and classical story genres in popular media coverage of racialised issues that change alongside social shifts in how 'race' is lived (Jacobs 2000). Nevertheless, these factors tend to be neglected in more general writing about narrative and social change.

\section{Narrative connections}

To examine narratives’ syntactic strategies for negotiating social change, I am going to deploy the intermediary concept of 'connection.' Connection describes both narrative associations, and social linkages, that are precursors, preconditions or catalysts of change. It signifies tying together - not synthesising, but making linkages that are contingent and reversible. It leaves open the possibility of disconnection, also. The concept allows us to think about how change may be pursued symbolically and microsocially through story genres and rhetoric. This understanding of narrative connection is consistent with some social network accounts of the 12 
Narratives, connections and social change

relations between social and cultural structures, but does not share their concerns about where to locate agency (Emirbayer and Goodwin 1994). Instead, it draws on Iris Marion Young's (2006) socio-political explanation of responsibility and global justice within an account of 'social connection', rather than liability. Young relates responsibility and justice to the processes that connect us with others: "some structural social processes connect people across the world without regard to political boundaries" (2006: 101). She describes social connection as characterised, where it promotes responsibility and justice, by five factors: Non-blaming; reference to contextual conditions which allow for explanation without personal blaming; orientation towards the future rather than the past, and a collective framing of explanations. In relation to responsibility and justice, therefore, this model "does not isolate perpetrators; it judges background conditions for action; it is more forward-looking than backward-looking; its responsibility is essentially shared; and it can be discharged only through collective action" (2006: 102).

Though 'social change’ encompasses shifts in many directions, it is generally understood as indicating the kind of progressive change, moving towards social justice and responsibility, that Young describes. This does not mean that social connections have fixed characters or outcomes; they are fluid, contradictory and repeatedly renegotiated (Hirst 1993; Mouffe 2006). Adopting Young's account does, however, suggest that narratives which promote social connections of the kind Young describes, may be able to contribute to progressive social change. This is not, of course, all that connecting narratives do. Working as sociomoral constructors of selves and social groups, they may justify the past, generate nostalgia, consolidate the status quo 
Narratives, connections and social change

or provide a manifesto for regressive, as much as progressive, social change. Moreover, narratives are not all connective; many work, in progressive or regressive directions, via disconnecting strategies which operate against precisely the directions described by Young. However, narrative has a particular relation to those directions, because it is by definition concerned with meaningful movements, associations and syntheses, and only secondarily with the dissociations and ruptures that inevitably also constitute it. In addition, a number of narrative researchers have suggested, from different perspectives, that narrative has a 'forward-looking' orientation of the kind Young specifies through its imbrications in audience (Bamberg 2006: 1401), its invocations of what is to come via its revisions of its past (Freeman 2009) and its dispossession from its author by the aspects of it that cannot yield to symbolic narrative form and that always make it unsatisfactory, needing to be done again (Butler 2005) Here, I am going to take up the last suggestion, which also places narratives as attempts to give accounts of “constitutive beginning and origins” (although these always escape them), and which thus positions them in close alignment with Young's other criterion of contextualised explanation.

\section{Narrative connection strategies}

Many rhetorical and genre strategies of connection appear within narratives. As is widely recognised, some such strategies are based on the body, which grounds many of the metaphors we live by (Lakoff and Johnson 2003) and which can play a key role within stories of political and national connection, as Gobodo-Madikizela’s (van der Merwe and Gobodo-Madikizela 2007) account of South African narratives of forgiveness in the post-apartheid context, via the establishment of rhetorically embodied relations to the other, demonstrates. Sometimes the concern with the body is physicalised, expressed by the body in a kind of gestural speech that 
Narratives, connections and social change

works to include difficult-to-express experiences within narratives and this to build a nonlinguistic bridge between the narrator and their audience (Peolson and Hyden). Another carefully explored set of strategies rests on the rhetorics and genres of time within narratives, which may seem to serve more or less straightforwardly to chart progressive connections or disconnections - but which are also syntactically and semantically highly variable (Brockmeier 2008 ) and which may indeed map out quite variable forms of time as ways of marking narrators’ forms of connection with others -for instance, in the case of chronic pain, narrators may use a turning point time rhetoric to connect this inaccessible experience to others; or backshadowing, retrospective, or sideshadowing, what-if strategies; or a vortex time which represents illness, while also registering its inexplicability (Bulow and Hyden 2003). Smaller-scale rhetorical and genre strategies include those focused on individual rights, political citizenship, or the psychological self.

Here, I consider two strategies of connection within narratives: those of similarisation and familiarisation, which have been less addressed, but which are wideranging, though not obvious, in the first case, and less frequent, but notably powerful, in the second. These strategies work both through genres and at a lower level through rhetorical tropes. The two strategies often occur together, and the second could be viewed as a subset of the first; this makes the consideration of both a useful exercise in distinguishing related connection strategies.

I shall suggest that both similarisation and familiarisation generate connections that can support progressive social change. To illustrate this argument, I shall focus on narratives produced within the HIV pandemic. The pandemic is not just an illness; it is characterised also by major psychological challenges and large financial, social and political demands. It is having 
Narratives, connections and social change

wideranging and longlasting effects, particularly in high-prevalence subsaharan African countries, on economies, education and health services, and everyday lives. Social change is clearly required if HIV prevention, treatment and care are to be addressed satisfactorily longterm. Experiential narratives appear to be a key aspect of creating social collectivity and change around this personally experienced, often stigmatised and silenced condition (Plummer 1995). My account of the strategies exemplified here in relation to HIV may also have some applicability to links between narratives and social change in other circumstances. In particular, such strategies may appear in narratives produced within other situations of crisis and exclusion where social change is at issue.

\section{Similarisation}

I want to start by examining some data from my UK study, which began in 1993 and is still continuing, of people's narratives of living with HIV. The research has involved around 80 people living with HIV, 50\% women, two-thirds in London, in up to five semi-structured interviews, addressing forms of support for living with HIV- medical, social and voluntary sector, family and friendship networks, media and faith. Analysis addresses interview content and also narrative form, because participants frequently use the interviews to tell their HIV life story, or structure significant amounts of interviews in narrative ways (see 2003, 2006, 2008 for further accounts)

The research participants consistently work at narrating themselves within, or back into, social formations defined by HIV, but also by family, friendship and citizenship. The most frequent language of connection is that of narrative similarisation, that is, tropes and genres that work 
Narratives, connections and social change

within stories to generate connection within and across HIV statuses through similarity. For instance, a middle class white British gay male interviewee, John (not his real name), living with HIV since the 1980s, repeatedly, across five interviews, drew comparisons between himself and HIV positive people apparently different from him - African migrants, drug users, people diagnosed later than he, heterosexual women and men, and younger gay men. In 2008, describing his conversations with newly-diagnosed people at an HIV service organisation, for example, he narrated similarities across time in reactions to diagnosis and concerns about medication's sideeffects, and to drive these stories forward, repeatedly compared his own experiences to those of HIV positive heterosexual men and women, and younger gay men:

John: I think, the, the shock factor is still there for a lot of people,/mhm/'I didn't think it would happen to me,' and of course now, I mean when I was diagnosed it seemed to be exclusively gay men but now we’ve got mainly heterosexual men and women... So, there's that sort of shock, horror...well we do get young gay men coming in also, one of their main concerns ... is 'I heard the drugs will make me have skinny arms and legs and a belly’ and all the rest of it... and a lot of them are almost scared to start, um, (antiretroviral) therapy because of what it will do to them $/ \mathrm{mhm} /$...It's alright for me to say 'well I’m fifty and I look like this’ (affected by lipodystrophy)...because I did look good in my twenties...So I don’t, so I shouldn’t, I don’t (judge), I can understand where they're coming from.

The study material also contains many narratives that establish similarity through generic plot commonalities. A number of interviewees, for instance, have told stories about "coming out” as gay men, alongside stories about “coming out” as HIV positive. Some heterosexual 17 
Narratives, connections and social change

women also used a “coming out” genre to talk about HIV (*). These genred narrative connections tie together the stories of gay men and women, and the stories of HIV positive heterosexual women and gay men, lending a starting point of stigmatisation and oppression and a powerful plot of emancipation to the HIV stories.

Collectively developed and told stories can be important means of gathering people together into associations that allow for social and political change (Plummer 1995). The narrative connections I have described, built up through a genre's plot, contribute to such processes in a distinct way. Through their representational mapping and performance of progression, they generate significatory and social connection. By these means, they go beyond the assertion of an experiential link, or the manifestation of commonalities in narrative content, to generate a common 'coming out' genre. Narrators of many silenced and stigmatised conditions can draw on this genre to generate collectivising and emancipating stories.

Such strategies have limits. Likenesses are declared within a bounded field; plot parallels are not exact. John noted that much of the fear he and his friends felt in the pre-treatment 1980s and early 1990s was lacking among the newly diagnosed. Younger gay men particularly commented that their sexual coming out was much easier than 'coming out' as HIV positive sexuality is not after all a potentially fatal illness. These examples of the limits of similarisation recall Tilly's (2002) emphasis on stories’ ability to produce difficulties and contradictions, as well as similarities - but also, a recognition of these apparent problems. The narrative similarisation strategies within the interviews are rhetorics and genres not of full identity, but of mobile and multiple identifications (Hall 1990), or equivalence (Mouffe 2006). They are not about total 
Narratives, connections and social change

“community” so much as about social associations or neighbourliness.

The most obvious criticism of any argument that moves from narrative strategies within interviews to social change, is that interviews are a particular kind of communication, not comparable to other social actions or interactions. However, in this study, interview talk was likely to overlap significantly with everyday talk about HIV, because participants were recruited via HIV organisations and were often, as in the cases of John, involved with HIV-related services and friendship networks. A strategy of similarisation deployed within interview narratives about HIV was, then, likely to be an important aspect of participants’ HIV-related talk more generally, where it could work to build alliances between HIV-positive people, and between HIV positive and HIV negative people. In John's 2008 interview, this possibility was supported when his stories about connections between himself and newly-diagnosed people were followed by a story of helping such people, through their and his similarities:

John: ...to go back to the newly diagnosed people, I'm talking to quite a lot of them I suppose, um, yes I find it very interesting really to hear their concerns and to help them, if I can possibly help them at all I can tell them my own experiences and the experiences of friends and that sort of thing...

Here, the links between similarising stories and social change lie only in self-report. However, the form of change which John invokes is itself based in stories, not too different to those told in the interviews, that create connections between HIV positive people with similar diagnosis experiences, across sexualities and periods of the epidemic. Moreover, broader interview material and field notes about John's social and political engagements support his claim to be involved in an HIV activism that includes people living with HIV in very different 19 
Narratives, connections and social change

health and social conditions, through his long history of work as a volunteer in a number of organisations dedicated to providing HIV services. Of course, his stories of connection may stem in part from such work; but these stories seemed also to be operating as templates for his continuing engagement.

Writing in the mid-1990s, Kenneth Plummer argued that intimate disclosure stories about AIDS, such as the ones in my study, 'help organise the flow of interaction' and build communities around the virus; but they look outwards and towards the future too. They are maps 'for action'; they 'make certain worlds more plausible'; they 'heal' or normalise HIV (Plummer 1995: 173-5; see also Carricaburu and Pierret 1995). In Plummer’s account, such stories do indeed work by similarisation, generating connections between different people living with HIV, and bringing HIV into relation with the non-HIV-affected world, in order to pursue an agenda of social connection very close to that non-blaming, collectivising one described by Young (2006).

Similarisation as a narrative strategy can, then, be said to show signs of working to produce social change through HIV narratives. Perhaps this might be true also for other stigmatised personal issues which generate intimate disclosure narratives. In the HIV case, moreover, similarisation narratives seem consistent with Young's social connection model. They are future-directed and oriented at collectivity, even when individual characters are at stake in for example media representations; they avoid blame; they pay attention to precise local conditions yet they also construct conditions of similarity that allow for social change. Again, similarising narratives' ability to instantiate these characteristics could be predictive of their social effectivity more generally, beyond the HIV field.

Similarisation is a widespread and powerful, albeit often implicit, connection strategy 20 
Narratives, connections and social change

within narratives. There are large amounts of data related to this strategy that allow us to consider in detail its potential social change effects, even though those data often go unrecognised. I want now to move on to a narrative strategy that is less frequent, though more obvious, and perhaps more easily recognised.

\section{Familiarisation}

Familiarisation relies on a more specific form of connection than similarity: that of biological, familial relationships, or other relationships that render people part of the same human "family". The familiarisation strategy of narrative connection uses tropes of family, person, and human within stories, and a narrative genre based on the development of these categories, within which personal and social progression proceeds through the struggle to realise a family-like structure. As with similarisation, familiarisation rarely constitutes the principal content of stories. It is, rather, a strategic element within stories, which allows them to work. Familiarisation makes a stronger connection claim than similarisation, based on the powerful ability of "family" to create associations. Familiarisation may still, like similarisation, create relations of equivalence, but its connections come closer to identifications, albeit temporary and partial ones.

To demonstrate the effectiveness of this narrative connection strategy, I want to draw on data from my smaller South African study of HIV support, also involving one and in some cases two semi-structured interviews, with 38 people - 29 of them women - living with HIV, conducted in 2001-4 (2007). Again, these interviews focused on support for living with HIV. Once more, a great deal of data was obtained, though not asked for, in narrative form. Similarisation was, here too, a common strategy of narrative connection. However, connection narratives in this second dataset, produced under conditions of much greater resource constraints - low treatment access, 21 
Narratives, connections and social change

high unemployment, a large and devastating epidemic - have familiarisation as an additional prominent stylistic feature.

Familiarisation is powerful in popular discourse, in South Africa and elsewhere. It appeared to some extent also in the data from my UK; but it was very direct and frequent within the South African HIV stories. In those embattled epidemic circumstances, it was perhaps not surprising that narrative strategies were more explicitly familial than in the UK context, rhetorically opposing stigmatisation and building community. Interviewees frequently named friends, volunteers, community workers, medical staff, activists, even NGOs, as metaphorical “brothers” and “sisters,” “mothers” and "fathers”. (see also Nguyen 2010; Robins 2008). HIV itself was part of this family, like a kinsperson living alongside you: “I talk to it personal,” one interviewee said. Moreover, the personhood of the person living with HIV was frequently claimed in a familiarised way, in relation to a broader national or human family. Interviewees reported telling HIV negative or unknown-status friends and family that they still have the same connection - "I am still me”, “I am a person like any other”, “do not hate me, such that you would not even use the plate I have eaten from.” They proposed an ethics of common humanity between HIV positive people and others - “we must treat people with HIV kindly”; and emphasised the nationwide salience of the epidemic across all age, class and gender boundaries. Interviewees' familiarising narratives also tied their narrators into transnational collectivity. Yoliswa for example, a young woman enrolled on an international NGO’s pilot antiretroviral treatment programme, described the NGO doctors as motivated by a love that created transnational family:

Yoliswa: I know once I have problems I'll go to (international NGO) doctors. They are 
Narratives, connections and social change

so good to us.... They are so good. We appreciate what they are doing to us because they don’t get anything out of it. ...We are not even coming from the same nation, why would they care. That's why I’m saying it’s coming from out of love, it’s coming out of love.

The majority of familiarisation stories among these data, though, made connections between people living with HIV. At a time of frequent stigmatisation of HIV positive people, little public disclosure, and almost no treatment access, these familialising connection narratives worked powerfully to establish commonality between HIV positive people, particularly within support groups. This commonality seemed to ground other forms of change $(*)$. Phumla, for instance, diagnosed for around a year, was now planning to disclose and educate people in her neighborhood, and narrated her progress towards this point through her support group 'family':

Phumla: The first thing I noticed there, we are all happy for each other. We treat each other as we are same family born of the same parents. For instance if I say I have nothing at home, one would pop out maybe five rand and say 'here take it'. If you say that you do not have food at home, no-one will gossip about you. We live like we are children of the same family. That is what I liked.

Were such familiarising strategies substitutes for negative or untellable stories of biological families in the HIV epidemic? This seems unlikely. Most interviewees had, albeit at a time of community silence, disclosed their status to at least one family member, with positive results. Phumla had told her husband; Yoliswa had told her family members. The familiarising connections they narrated thus seemed to operate independently from and in addition to these literal family relationships. 
Narratives, connections and social change

Again, this study did not investigate such stories’ connections with everyday speech, still less with lived social connections. Other information from the interviews and from field notes, however, indicates that Yoliswa spoke publically about her status in many different fora, and that Phumla’s support group attendance had generated a network of HIV positive friends and plans for activist involvement. These involvements seemed to be the results of the familiarising narrative strategies demonstrated in the interviews, as much as their precipitators. For familiarising narratives have a special place in establishing commonality and supporting change around stigmatised and silenced conditions such as HIV. With such conditions, open selfrepresentation - 'speaking out' - is recognised as an important, even essential aspect of efforts to combat them, and of change in opinions and actions (Campbell et al. 2007; Epstein 2007; Robins 2008; *; Treichler 1989). Familiarising strategies for 'speaking out', that create powerful connections, both between people who share the stigmatised condition, and between people with different relationships to that condition, are likely to have marked effects. The social movements that were narrated within Phumla's and Yoliswa's own interviews, from clinics and support groups outwards, towards wider familiarised communities of people living with and affected by HIV, support this supposition.

Familiarisation, like similarisation, has its limits. Familiarising narratives of connection are always situated in precise sociopolitical contexts which shape their effects. In South Africa, this context included a recent history of both HIV denial and activism, a political tradition of collectivised storytelling derived from the Truth and Reconciliation Commission, the antiapartheid struggle, and longer-established notions of ubuntu or collective human construction 
Narratives, connections and social change

and responsibility; and a conservative familialism which could make familial narratives patronising or dismissive for younger people and women. Yoliswa for instance told a story of one doctor's use of a familiarising trope to brush aside her concerns and the life of her child:

Yoliswa:...doctors become so rude to us when we take these babies to hospital, he will tell you, 'mama you know this baby is HIV positive and there is nothing we can do, you know there is no cure for HIV'.

A further limitation of narrative familiarisation is that it undoes itself through its own strength. To declare a familial relationship between people of the same or different HIV statuses is not just to build community, but also to claim human, 'family' rights from those who are not HIV positive. Everyone, even those most distanced from the epidemic, is claimed as part of the HIV-affected family. Familiarising metaphors thus make claims that powerfully resist stigma, but that may be contested in resource-described circumstances - for example, where people living with HIV require many resources, while others in their literal and metaphorical families are heavily underresourced. In such cases, familialised connections need to be renegotiated repeatedly in order to maintain, yet alone progress, social change. Several women interviewees reported habitually saying, to family and friends, 'I am still your sister' or, 'I am like your sister,' continually recognising and repairing the social rifts the condition continues to make.

It could be argued that I have been overinterpreting the familiarising narrative strategies in the South African data. Family terms of address such as 'sister', 'brother', 'mother' and 'father' are socially widespread and frequent in South Africa outside the biological family, as in many other national contexts. But this way of speaking takes on particular salience when relationship is being claimed within or to stigmatised conditions. When, for instance, a support group 25 
Narratives, connections and social change

acquaintance of Phumla's, cointerviewed with her, refers to her as 'sister,' this everyday term normalises their relationship within the HIV-affected human 'family.' When an interviewer of undisclosed status calls on an interviewee to contribute by saying, "and you, sisi?' , a rhetorical commonality is assserted between HIV positive people and apparent 'others'. The salience of these familiarising tropes was very strong within research participants' stories at this particular moment, when people were trying to establish commonalities within and across a highly stigmatised condition.

As in Young's model of social connection as the route to social responsibility, familiarisation narratives are characterised by a strong commonality that enables collective, future-oriented thinking. This narrative strategy could encourage not just connection, but a homogenisation that elides historical and social differences, or a conservatism that fixes identifications. I have argued, however, that familiarisation does not necessarily produce such homogenising or paralysing identifications. Often, the limits of familiarisation that familiarisation itself conjures, generate debated equivalences, rather than identities, between familiarised citizens.

\section{Conclusion}

Similarisation and familiarisation work together in narratives like those about HIV considered here. They are mobile and open in their meanings. They undermine themselves, which stops them ossifying. They build equivalence rather than identity within social connections (Mouffe 2006). They operate according to the model Young lays out, contextualising stories, collectivising rather than apportioning blame, orienting towards the future. The polysemies and contradictions of such strategies could make narratives inactive and 26 
Narratives, connections and social change

conservative. Moreover, the concreteness of familiarisation, particularly, could promote regressive social change. However, in relation to HIV narratives, and perhaps, narratives of stigma and crisis more generally, strategies of connection like those examined here often work positively alongside other forms of material change, or provide foundations for them. They allow for possible or imagined social shifts, and they operate as pragmatic, contingent suggestions about, inducements to and instantiations of social change.

This article has argued that we can describe 'syntactic,' rhetorical and genre narrative strategies that promote social connection and change, rather than assuming that this happens solely through narratives' content and contexts. Such descriptions detail the processes demonstrated in Obama's storytelling, and sketched in Tilly’s accounts. They strengthen the impact of finer-grained work like that of Polletta (2006) and Plummer (1995). Here, I have describe two common and striking processes - similarisation and familiarisation - which operate with some generality across conditions of social change, particularly around stigmatised conditions, while also pointing out their limitations. There are many other strategies within narratives that operate in related ways - tropes of embodiment and temporality, for example, and narrative genres of self-development and political action. Analysing such strategies of narrative connection is a way of working out how narratives and social change are articulated together an issue with which many researchers are concerned, but which is hard to address precisely. Performing such analyses also moves narrative research itself into a form of pragmatism which allows narrative researchers to work together across different epistemological and ontological perspectives, which is very close to how narratives of social change work, and which allows narrative research to work in dialogue with the narratives themselves in understanding and promoting social change. 27 
Narratives, connections and social change 
Narratives, connections and social change

\section{REFERENCES}

Andrews, Molly. 2007. Shaping History. Cambridge: Cambridge University Press

Azarian-Ceccato, Natasha. 2010. “Reverberations of the Armenian genocide: Narrative’s intergenerational transmission and the task of not forgetting.” Narrative Inquiry 20, 1: 106-23.

Bamberg, Michael. 2006. “Stories: Big or Small—Why Do We Care?” Narrative Inquiry 16, 1: 139-47.

Barthes, Roland. 1977. The Pleasure of the Text. New York: Hill and Wang.

Bertaux, Daniel. 1981. Biography and Society. London: Sage

Beverley, John. 2004. Testimonio: On the Politics of Truth. Minneapolis, MN: University of Minnesota Press.

Brockmeier, Jens (2008) “Stories to Remember: Narrative and the Time of Memory”. Storyworlds: A Journal of Narrative Studies 1, 1: 99-114.

Bruner, Jerome. 2002. Making Stories: Law Literature, Life. Cambridge, Massachusetts: Harvard University Press 
Narratives, connections and social change

Bülow, Pia and Hydén, Lars-Christer. 2003. “In Dialogue with Time: Identity and Illness in Narratives about Chronic Fatigue. Narrative Inquiry 75, 1: 71-97.

Butler, Judith. 2005 Giving An Account of Oneself. Bronx, New York: Fordham University Press

Campbell, Cathy, Nair, Yugi, Maimane, Sbongile, Sibiya, Zweni (2007) “Building Contexts that Support Effective Community Responses to HIV/AIDS”. American Journal of Community Psychology. 39, 3-4:347-363.

Carricaburu, Daniele and Pierret, Janine. 1995. From biographical disruption to biographical reinforcement. Sociology of Health and Illness 17, 1: 65-88

Culler, Jonathan.2006 [1981]. The Pursuit of Signs. New York: Routledge

DIPEx. 2010. “People's Stories: See, Hear and Read their Experiences”. Retrieved 24 January 2010. (http://www.healthtalkonline.org/ )

Eastmond, Maria. 2007. “Stories as Lived Experience: Narratives in Forced Migration Research.” Journal of Refugee Studies 20 (2): 248-264.

Edley, Nigel. 2002. “The loner, the walk and the beast within: narrative fragments in the construction of masculinity”. Pp127-45 in Strategic Narrative edited by W. Patterson. Lanham Maryland: Lexington Books

Emirbayer, M. and Goodwin, J. 1994. “Network analysis, culture, and the problem of agency”. American Journal of Sociology 99, 6: 1411-54

30 
Narratives, connections and social change

Epstein, Helen. 2007. The Invisible Cure. New York: Farrar, Straus and Giroux

Foucault, Michel. 1980. History of Sexuality Volume 1. London: Allen Lane

Freeman, Mark. 2009. Hindsight. New York: Oxford University Press.

Georgakopoulou, Alexandra. 2007. Small stories, Interaction and Identities.

Amsterdam//Philadelphia: John Benjamins.

Gready, Paul. 2008. “The Public Life of Narratives: Ethics, Politics, Methods”. Pp 137-50 in Doing Narrative Research edited by M. Andrews, C. Squire and M. Tamboukou. London: Sage.

Green, G. (2009) The end of stigma? London: Routledge

Gubrium, Javer and Holstein, James. 2009. Analysing Narrative Reality. Thousand Oaks, CA: Sage.

Hall, Stuart. 1990. “Cultural Identity and Diaspora”. Pp 222-37 in Identity: Community, Culture, Difference edited by J. Rutherford. London: Lawrence \& Wishart.

Hearing Voices Network. 2010. “News and Events”. Retrieved 24 January 2010.

(http://www.hearing-voices.org/news.html ) 
Narratives, connections and social change

Hirst, Paul (1993) Associative Democracy. Cambridge: Polity Press.

Hydén, Lars-Christer and Brockmeier, Jens. 2009. Narrative, Health and Culture: Broken Narratives. New York: Routledge.

Hydén, Margareta. 2008. Narrating Sensitive Topics. Pp 121-36 in Doing Narrative Research edited by M. Andrews, C.Squire and M.Tamboukou. London: Sage

Hyvärinen, Matti, Hydén, Lars-Christer, Saarenheimo, Marja and Tamboukou, Maria. 2010. Beyond Narrative Coherence. Amsterdam: John Benjamins.

Jacobs, Ronald N. 2000. Race, Media and the Crisis in Civil Society: From Watts to Rodney King. Cambridge: Cambridge University Press.

Klein, Joe 2011 Hello Sunshine. Time February 11, 13,

Labov, William. 1997. “Some Further Steps in Narrative Analysis”. Journal of Narrative and Life History 7: 395-415

Lakoff, George and Johnson, Mark. 2003. Metaphors We Live By. Chicago, ILL: Chicago University Press 
Narratives, connections and social change

Linkins, J. (2010) “White House Press Corps’ Latest Obsession: Obama’s Emotional State.” 2 June, 2010. Retrieved 25 August, 2010. (http://www.huffingtonpost.com/2010/06/02/whitehouse-press-corps-1_n_597538.html )

MacIntyre, Alastair. 1984. After Virtue. Bloomington, Indiana: Notre Dame University Press

Merck, Mandy. 1993. Perversions: Deviant Readings. London: Routledge.

Mishler, Elliot. 1986 Research Interviewing. Cambridge, Massachusetts: Harvard University Press.

Mouffe, Chantal. 2006 [1993] The Return of the Political. London: Verso

Nguyen, Vinh-Kim. 2010. Republic of therapy. Bloomington, IN:Indiana University Press

Obamaspeeches.com (2008), “Manassas, Prince William County, Virginia, November 3, 2008

10.30pm - Night Before the Election”. Retrieved January 24, 2010

(http://obamaspeeches.com/E-Barack-Obama-Speech-Manassas-Virgina-Last-Rally-2008-

Election.htm )

Plummer, Kenneth. 2001. Documents of Life 2. London: Sage

Plummer, Kenneth. 1995. Telling Sexual Stories. London: Sage 
Narratives, connections and social change

Polletta, Francesca. 2006. It Was Like A Fever. Chicago: Chicago University Press

Polletta, Francesca and Lee, J. 2006. “Is Telling Stories Good for Democracy? Rhetoric in Public Deliberation after 9/11”. American Sociological Review, 71, 5: 699-723. October.

Portelli, Alessandro. 2007. The Order Has Been Carried Out. London: Palgrave Macmillan

Portelli, Alessandro. 1990. The Death of Luigi Trastulli and Other Stories. Binghampton, New York: SUNY Press

Radley, Alan. 2009. Works of Illness.London: InkerMen Press.

Ricoeur, Paul. 1991 “Life in Quest of Narrative.” Pp 20-33 in On Paul Ricoeur: Narrative and Interpretation edited by D.Wood. London: Routledge.

Riessman, Catherine. 2008. Narrative Methods for the Human Sciences. New York: Sage

Robins, Steven. 2008. From Revolution to Rights in South Africa. Durban: UKZN Press

Selbin, Brian. 2010. Revolution, Rebellion, Resistance - The Power of Story. New York: Zed Books. 
Narratives, connections and social change

Shaffer, Kay and Smith, Sidonie. 2004. Human Rights and Narrated Lives. New York: Palgrave Macmillan

Spivak, Gayatri.1996.”Diasporas Old and New: Women in the Transnational World.” Textual Practice 10: 245-69

Stanley, Liz. 1996. The Auto/Biographical I. Manchester: Manchester University Press

Stanley, Liz. 2009. Introduction: Narratives from Major to Minor: On Resisting Binaries in Favour of Joined Up Thinking. Sociological Research Online 14, 5. Retrieved 24 January 2010 (http://www.socresonline.org.uk/14/5/25.html )

Stevenson, Richard W. 2010. “A Narrative Vacuum”. Observer February 7, New York Times reprint, $1,4$.

Tilly, Charles. 2002. Stories, Identities and Political Change. Oxford: Rowman and Littlefield.

Tilly, Charles. 2006. Why? Princeton, New Jersey: Princeton University Press

Tilly, Charles and Tarrow, Sidney. 2006. Contentious Politics. New York:Paradigm

Todorov, Tzvetan. 1990. Genres in Discourse. Cambridge: Cambridge University Press.

Treichler, Paula. (1999), How to have theory in an epidemic: cultural chronicles of AIDS, Durham, 35 
Narratives, connections and social change

Duke University Press.

Van de Merwe, Chris and Gobodo-Madikizela, Pumla. 2007. Narrating our Healing. Cambridge: Cambridge Scholars Press

White, Harrison. 2008. Identity and Control. Princeton, NJ: Princeton University Press

$\mathrm{Xu}$, Shihing and Connelly, Michael. 2010. Narrative inquiry for school-based research. Narrative Inquiry 20, 2: 349-70. 
Narratives, connections and social change

Notes

' These accounts also put into question traditional narratological distinctions between 'story' and 'narrative', suggesting that the story as 'sequence of events' is not separable from but always imbricated in narrative; the terms are used interchangeably in this paper. 